\title{
ANALISIS PENGUASAAN KONSEP MATERI SISTEM REPRODUKSI PADA SISWA SMA NEGERI DI KOTA MATARAM
}

\author{
ANALYSIS OF HIGH SCHOOL STUDENT CONCEPT MASTERY ON THE REPRODUCTION SYSTEM \\ TOPIC AT THE CITY OF MATARAM
}

\author{
Monica Rizki Hairy“, Kusmiyati, M. Yamin \\ Program Studi Pendidikan Biologi, Jurusan PMIPA, FKIP, Universitas Mataram \\ Universitas Mataram, Jalan Majapahit No. 62 Mataram, Indonesia \\ *Email : Monicarizki96@gmail.com
}

Diterima: 19 Juli 2018. Disetujui: 24 September 2018. Dipublikasikan: 29 September 2018

\begin{abstract}
Abstrak. Tujuan dari penelitian ini adalah untuk mengetahui penguasaan konsep materi sistem reproduksi dengan menggunakan analisis instrument two-tier multiple choice tipe terbuka di SMA Negeri Se-Kota Mataram. Jenis penelitian ini adalah penelitian deskriptif. Populasi penelitian adalah seluruh siswa kelas XI MIPA SMA Negeri SeKota Mataram tahun ajaran 2017/2018 yang berasal dari 8 SMA Negeri di Kota Mataram. Pengambilan sampel dilakukan dengan teknik purposive sampling dan diperoleh peserta didik kelas XI MIPA dari SMAN 3 Mataram, SMAN 5 Mataram, SMAN 6 Mataram dan SMAN 8 Mataram sejumlah 280 peserta didik. Hasil penelitian menujukkan persentase penguasaan konsep kategori tidak paham konsep pada siswa kelas XI MIPA dari SMAN 3 Mataram, SMAN 5 Mataram, SMAN 6 Mataram dan SMAN 8 Mataram sebesar 70\%, 34\%, 59\%, dan 63\%. Sedangkan persentase kategori miskonsepsi pada pada siswa kelas XI MIPA dari masing-masing sekolah diatas adalah $26 \%, 51 \%, 41 \%$ dan $33 \%$. Begitu pula dengan persentase kategori paham konsep masing-masing sekolah yaitu $4 \%, 14 \%, 0 \%$ dan $4 \%$. Kesimpulan dari hasil penelitian menunjukan bahwa persentase penguasaan konsep siswa kelas XI MIPA SMA Negeri Se-Kota Mataram pada materi sistem reproduksi pada kategori tidak paham konsep sebesar 51\%, miskonsepsi sebesar 38\% dan paham konsep sebesar $11 \%$.

Kata kunci : penguasaan konsep,miskonsepsi, two-tier multiple choice tipe terbuka

Abstract : The purposes of this research are to know the percentages of student concept capability in grade Science XI on reproduction system material by using the Open-Type Two-Tier Multiple Choice at Mataram City State Senior High School. The type of this research is descriptive research. The research population is all students from 8 State Senior High School in grade science XI at Mataram City in academic year 2017/2018. Sampling was done by purposive sampling technique and 280 students were selected from Senior High School 3 Mataram, Senior High School 5 Mataram, Senior High School 6 Mataram, and Senior High School 8 Mataram. The results shown that the percentages of incapable of concept of students from Senior High School 3 Mataram, Senior High School 5 Mataram, Senior High School 6 Mataram, and Senior High School 8 Mataram are 70\%, 34\%, 59\%, and 63\%. Meanwhile the percentages of misconception are $26 \%, 51 \%, 41 \%$ and $33 \%$, and the percentages of concept capability are $4 \%, 14 \%, 0 \%$ and $4 \%$. The conclusion shown that the percentage of concept capability in grade Science XI on reproduction system material by using the Open-Type Two-Tier Multiple Choice at Mataram City State Senior High School which divided into three categories there are Incapable of Concept with the percentage $51 \%$, Misconception $38 \%$, and Capable of Concept $11 \%$.
\end{abstract}

Keywords : Concepts Capability,misconception, Open-Type Two-Tier Multiple Choice

\section{PENDAHULUAN}

Pembelajaran merupakan suatu proses interaksi antara guru dengan siswa. Salah satu tujuan pembelajaran sains adalah agar siswa memahami konsep, aplikasi konsep dan mampu mengaitkan satu konsep dengan konsep lainnya. Pada proses pembelajaran inilah siswa diharapkan memahami konsep yang diajarkan bukan hanya sekedar hafal. Kemampuan siswa dalam memahami konsep merupakan hal yang sangat penting karena konsep merupakan landasan untuk berpikir [1].

Setiap siswa telah memiliki pengalaman dan pengetahuan sendiri mengenai alam sebelum memperoleh pembelajaran di sekolah sehingga membentuk suatu konsepsi. Setiap orang mempunyai rumusan deskripsi sendiri terhadap suatu konsep tertentu. Setiap konsepsi yang berada dalam pikiran seseorang dapat terbentuk sedemikian rupa, berkembang dan mengalami perubahan yang 
disebabkan oleh pengalaman-pengalaman yang diperolehnya [1].

Pemahaman konsep merupakan kemampuan seorang siswa untuk tidak sekedar mengingat, tapi dapat menjelaskan kembali suatu defenisi, ciri khusus, hakikat, inti dan isi dengan menggunakan kata-kata sendiri, namun tidak mengubah kandungan makna dari informasi yang diterima. Hal ini sejalan dengan pendapat Johnson [2] yang mengungkapkan bahwa "pemahaman adalah kemampuan untuk menerangkan sesuatu dengan kata-kata sendiri. Menurut Engelhardt dan Bechner [3], dalam proses pembelajaran, siswa perlu memahami konsep secara benar, hal ini berhubungan dengan pemahaman mengenai arti fisis dari konsep yang dipelajari serta aplikasi konsep tersebut dalam kehidupan sehari-hari.

Menurut Tekkaya [4] miskonsepsi dapat berasal dari pengalaman yang biasa dialami oleh siswa. beberapa dari pengalaman tersebut berasal dari pengalaman sehari-hari. Jadi dengan adanya pengalaman, konsepsi yang dimiliki siswa terhadap suatu konsep dapat benar atau salah. Jika konsepsi siswa terhadap suatu konsep sama dengan konsepsi para ilmuwan, dikatakan siswa tersebut mempunyai konsep yang benar. Jika konsepsi siswa tentang suatu konsep berbeda dengan konsepsi para ilmuwan, dikatakan siswa tersebut mengalami miskonsepsi.

Penelitian sebelumnya tentang tidak paham konsep, miskonsepsi, dan paham konsep telah banyak dikaji [5-13]. Untuk mengidentifikasi penguasaan konsep seperti tidak paham konsep, miskonsepsi, dan paham konsep guru dapat melakukan evaluasi. Evaluasi adalah kegiatan mengidentifikasi untuk melihat apakah suatu program yang telah direncanakan telah tercapai atau belum, berharga atau tidak, dan dapat pula untuk melihat tingkat efisiensi pelaksanaannya [12]. Tujuan dari kegiatan evaluasi ini adalah untuk mengetahui apakah tujuan yang telah dirumuskan itu tercapai atau belum dan apakah materi pelajaran yang diajarkan di kelas sudah tepat.

Salah satu bentuk evaluasi yang dapat dilakukan adalah dengan pemberian tes dalam bentuk Two-Tier Multiple Choice Tipe Terbuka. Bentuk instrument tersebut menggunakan tes pilihan ganda dengan pertanyaan terbuka dimana siswa harus menjawab dan menulis alasan mengapa ia mempunyai jawaban tersebut. Jawaban-jawaban yang salah dalam pilihan siswa ini selanjutnya dijadikan bahan tes berikutnya [14-16]. Treagust dalam Suparno [17], menggunakan multiple choice dengan reasoning yakni siswa harus menulis alasan mengapa ia memilih jawaban itu. Hasil dari perhitungan skor dapat menjadi acuan dalam pengkategorian pemahaman konsep peserta didik.

\section{METODE PENELITIAN}

Penelitian ini adalah penelitian deskriptif. Populasi dari penelitian ini adalah seluruh siswa kelas XI MIPA SMA Negeri Se-Kota Mataram tahun ajaran 2017/2018. Sampel yang diambil dari penelitian ini adalah siswa kelas XI MIPA dari SMAN 3 Mataram, SMAN 5 Mataram, SMAN 6 Mataram dan SMAN 8 Mataram dengan total 280 siswa yang dilakukan dengan teknik pusrposive sampling. Pengumpulan data dilakukan dengan pemberian tes dalam bentuk Two-Tier Multiple Choice Tipe Terbuka.

\section{HASIL DAN PEMBAHASAN}

Berdasarkan Gambar 1 terlihat tingkat persentase tidak paham konsep pada siswa kelas XI MIPA dari SMAN 3 Mataram, SMAN 5 Mataram, SMAN 6 Mataram dan SMAN 8 Mataram sebesar $70 \%, 34 \%, 59 \%$, dan $63 \%$. Hal tersebut dapat dikarenakan pembahasan materi yang belum diselesaikan oleh guru mata pelajaran tersebut. Salah satunya karena metode mengajar dan ketidaktersediaan waktu pembelajaran yang cukup dikarenakan waktu pembelajaran di semester genap lebih sedikit dibanding pada semester ganjil. Sehingga guru hanya memberikan tugas kepada siswa secara berkelompok tanpa adanya ataupun pembahasan atau presentasi mengenai materi tersebut dilakukan secara singkat.

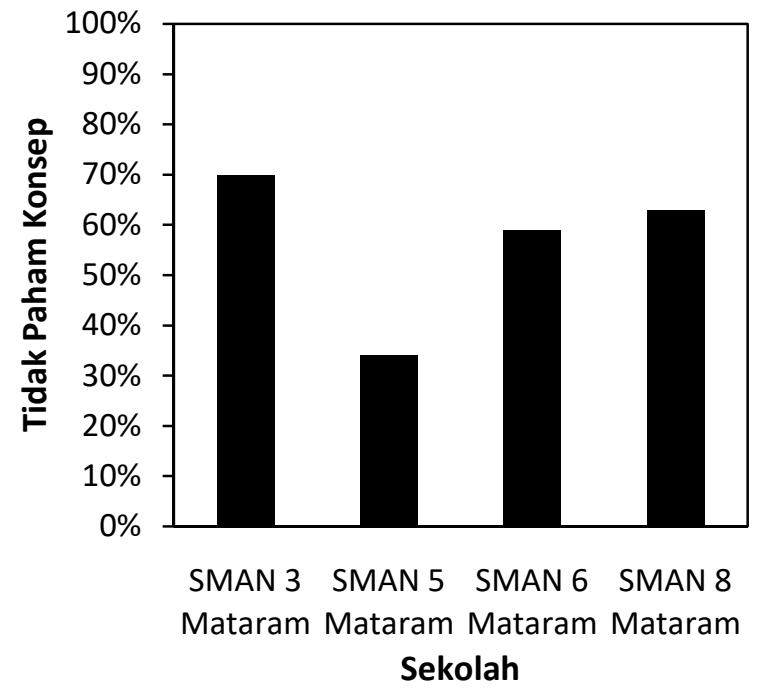

Gambar 1. Penguasaan Konsep Kategori Tidak Paham Konsep Siswa Kelas XI SMA Negeri Se-Kota Mataram

Untuk menanggulangi hal tersebut siswa diminta untuk membaca sendiri atau belajar sendiri mengenai materi yang belum disampaikan tersebut atau diberi pekerjaan rumah (PR). Menurut Suparno 
[18] PR yang tidak dikoreksi dapat menambah tingkat miskonsepsi pada siswa karena siswa yang memiliki miskonsepsi akan tetap memiliki konsep yang salah karena merasa pekerjaannya benar. Hal tersebut dapat menimbulkan kesulitan belajar kepada siswa.

Menurut Hamalik [18], kesulitan belajar dapat disebabkan oleh berbagai faktor, dua diantaranya yaitu minat belajar dan gaya belajar. Setiap siswa memiliki minat belajar yang berbedabeda. Minat menentukan sukses atau gagalnya kegiatan sesorang. Minat yang tinggi akan meningkatkan motivasi, sedangkan kurangnya minat menyebabkan kurangnya perhatian dan usaha belajar, sehingga menghambat studinya. Selain minat, kebiasaan belajar yang juga dapat menjadi faktor kesulitan belajar bagi siswa. Selain itu kesulitan belajar siswa juga disebabkan oleh kelemahan metode yang digunakan. Bagi peserta didik berusia muda, kemampuan berpikir rasional mereka masih terbatas. Hal ini disebabkan karena usia mereka yang muda membutuhkan kematangan dalam berpikir rasional mengenai suatu konsep atau teori. Kemungkinan lain adalah desain pembelajaran yang diterapkan guru pada sekolah tersebut kurang menarik bagi siswa, sehingga siswa kurang berminat untuk memperdalam pengetahuannya hingga ke persoalan aplikatif.

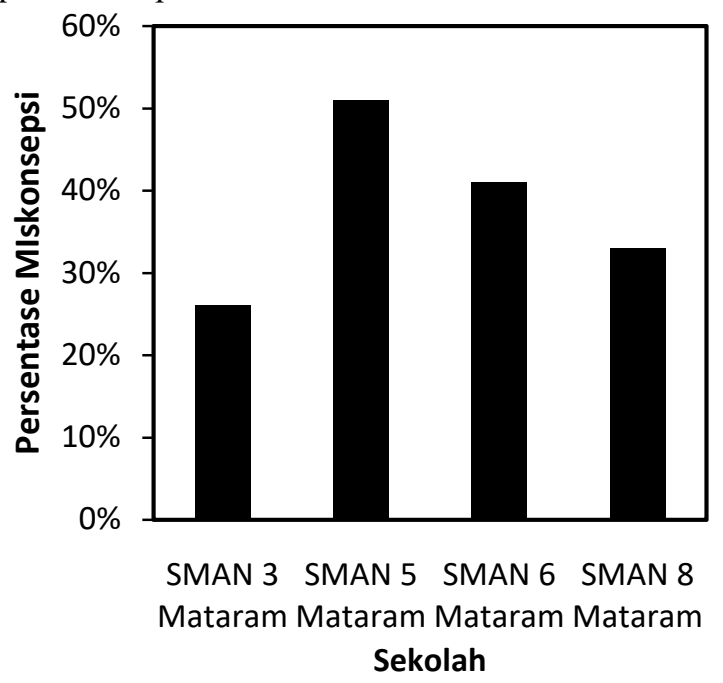

Gambar 2. Penguasaan Konsep Kategori Miskonsepsi Siswa Kelas XI SMA Negeri Se-Kota Mataram

Gambar 2 menunjukkan persentase jumlah siswa yang mengalami miskonsep pada materi sistem reproduksi yaitu sebagai berikut SMAN 3 Mataram sebesar 26\%, SMAN 5 Mataram sebesar 51\%, SMAN 6 Mataram sebesar $41 \%$ dan SMAN 8 Mataram sebesar 33\%. Berdasarkan gambar 3 terlihat persentase miskonsepsi siswa kelas XI SMA Negeri Se-Kota Mataram. Sekolah yang memiliki persentase miskonsepsi yang paling tinggi adalah SMAN 5 Mataram dan yang paling rendah adalah SMAN 3 Mataram. Sekolah lainnya memiliki tingkat miskonsepsi yang rendah-sedang dikarenakan tingkat tidak paham konsep lebih tinggi dibandingkan dengan tingkat miskonsepsi. Cara pembelajaran masih dilakukan dengan cara membagi siswa menjadi beberapa kelompok yang nantinya masing-masing kelompok akan mempresentasikan hasil diskusi mereka. Pada beberapa sekolah guru sempat membahas materi presentasi kelompok meskipun pembahasan yang dilakukan tidak secara menyeluruh. Hal tersebut dapat menyebabkan pemahaman konsep siswa yang tidak utuh dan tidak kuat menyebabkan kurangnya kemampuan penalaran siswa saat menghadapi pertanyaan aplikatif yang berisi penyebab dan cara penularan atau penyebaran penyakit pada sistem reproduksi manusia. Akibatnya siswa mengalami miskonsepsi. Pendapat ini didukung dengan pernyataan Suparno [17] bahwa siswa yang hanya menangkap sebagian materi memiliki pemahaman yang tidak utuh terhadap materi tersebut, sehingga dapat mengalami miskonsepsi.

Pendapat ini didukung oleh Murni [20] yang menyatakan bahwa metode mengajar yang digunakan guru dapat menyebabkan siswa mengalami miskonsepsi. Strategi pembelajaran yang diterapkan menyebabkan siswa hanya terfokus untuk mempelajari submateri yang harus dipresentasikan oleh kelompoknya, sedangkan sub materi lain hanya dipelajari sekilas, yaitu saat memperhatikan presentasi atau pembahasan kelompok lain.

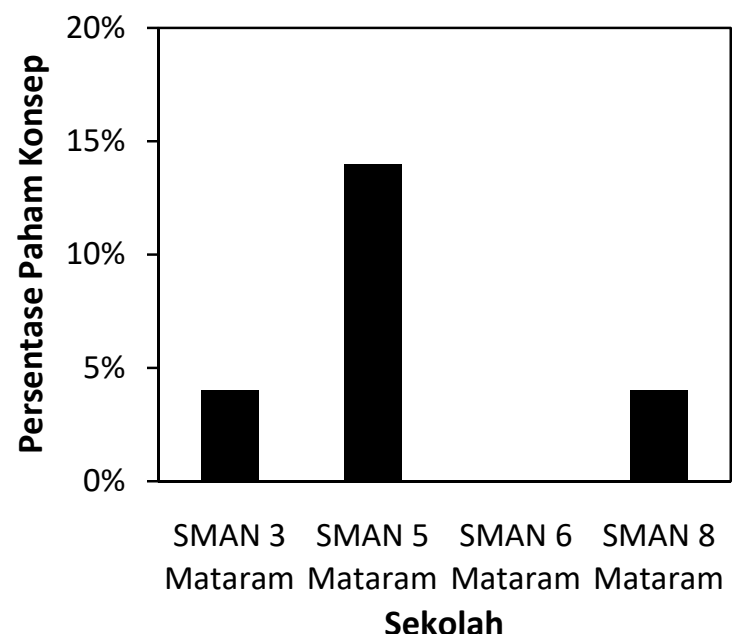

Gambar 3 Penguasaan Konsep Kategori Paham Konsep Siswa Kelas XI SMA Negeri Se-Kota Mataram

Kesalahan dalam pemahaman konnsep (miskonsepsi) merupakan salah satu masalah besar 
dalam pendidikan yang harus segera diselesaikan. Miskonsepsi banyak terjadi tidak hanya pada siswa saja tetapi dalam buku pun masih ditemukan miskonsepsi, akibatnya banyak pemahaman keliru yang harus segera dibenarkan. Hal yang menjadi salah satu penyebab terjadinya miskonsepsi adalah adanya penekanan dari guru yang mengharuskan siswa agar hafal terhadap suatu konsep, sehingga siswa cenderung hafal tanpa paham apa yang dihafalnya, akibatnya miskonsepsi pun akan terjadi. Seharusnya, guru lebih menekankan dalam hal pemahaman konsep, karena dengan pemahaman inilah materi bisa terkuasai untuk jangka waktu yang lama dan miskonsepsi pun dapat diminimalisir.

Berdarsarkan gambar 3 terlihat persentase paham konsep dari ke empat sekolah sebesar $4 \%$, $14 \%, 0 \%$, dan $4 \%$ yang menunjukkan bahwa SMAN 5 Mataram memiliki persentase paham konsep tertinggi, hal ini dapat dipengaruhi beberapa hal, diantaranya karena SMA Negeri 5 Mataram merupakan sekolah favorit di Kota Mataram yang melakukan seleksi ketat saat penerimaan siswa sehingga siswa yang bersekolah di sekolah tersebut termasuk siswa-siswa pilihan, selain itu kelengkapan fasilitas sekolah juga dapat mempengaruhi seperti ketersediaan media dan alat-alat pembelajaran, seperti LCD dan juga penggunaan video. Hal-hal tersebut sepertinya masih kurang dimiliki oleh sekolah lainnya. Berdasarkan keterangan siswa SMA Negeri 5 Mataram mereka sudah menggunakan media audio-visual seperti video dalam kegiatan pembelajaran. Hal tersebut berbeda dari beberapa sekolah lain yang masih belum secara maksimal menggunakan media pembelajaran. Seperti keterangan dari siswa SMA Negeri 3 Mataram dan SMAN 6 Mataram, pembelajaran materi sistem reproduksi manusia tidak menggunakan media audiovisual berupa gambar animasi atau video animasi sehingga siswa hanya membayangkan mekanisme/proses sambil melihat gambar. Hal ini diduga menjadi penyebab tingginya miskonsepsi pada hampir semua materi sistem reproduksi manusia. Imajinasi siswa dalam membayangkan proses yang terjadi dalam tubuh manusia berbedabeda sehingga menimbulkan perbedaan penafsiran tentang mekanisme yang benar. Hal ini sesuai dengan pendapat Onansaya [21] bahwa media audio-visual sangat efektif untuk menunjukkan suatu konsep simulasi/proses, sehingga ketiadaan wahana/media untuk menyamakan persepsi tentang konsep proses yang benar atau untuk mengecek konsep yang dipahaminya benar atau salah.

Banyaknya hari libur pada semester genap dapat berpengaruh terhadap waktu belajar siswa di sekolah, hal itu disebabkan oleh dilakukan persiapan ujian nasional untuk kelas XII, serta adanya hari-hari libur nasional. Namun hal tersebut seharusnya dapat diantisipasi oleh guru saat penyusunan RPP agar dapat mencapai tujuan pendidikan yang diinginkan. Karena alasan mendasar guru harus merancang pembelajaran dengan baik adalah adalah agar dapat mencapai tujuan pendidikan yang diinginkan [22]. Cakupan materi sistem reproduksi manusia cukup luas dan siswa membutuhkan waktu lebih untuk penguasaan materi sehingga alokasi waktu harus diperhatikan. Siswa memerlukan bimbingan guru terkait materi aplikasi untuk memastikan alur berpikir dan pemahamannya sesuai dengan teori yang benar sehingga tidak mengalami miskonsepsi. Seperti yang dikemukakan Jufri [22] Guru sains professional tidak cukup menguasai fakta-fakta dan konsep-konsep sains semata, tetapi harus memiliki pemahaman mendalam tentang sains terutama sistem koheren antara fakta, konsep, inkuiri ilmiah (scientific inquiry) dan menyelesaikan masalah.

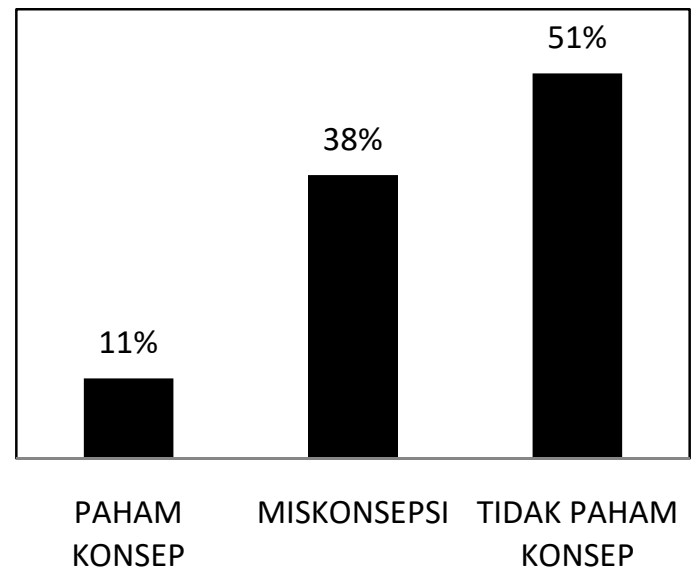

Gambar 4. Penguasaan Konsep Sistem Reproduksi Siswa Kelas XI SMA Negeri Se-Kota Mataram

Berdasarkan analisis yang telah dilakukan, didapatkan persentase penguasaan konsep dari siswa SMA Negeri Se-Kota Mataram secara keseluruhan yang dibagi menjadi tiga kategori, yaitu peserta didik tidak paham konsep sebesar $51 \%$, dengan jumlah peserta didik 144 orang, persentase peserta didik miskonsepsi sebesar $38 \%$ dengan jumlah peserta didik sebanyak 106 orang dan peserta didik paham konsep sebesar $11 \%$ dengan jumlah peserta didik sebanyak 30 orang seperti yang terlihat pada gambar 4.

\section{KESIMPULAN}

Persentase jumlah penguasaan konsep peserta didik di SMAN Se-Kota Mataram kelas XI MIPA dari SMAN 3 Mataram, SMAN 5 Mataram, SMAN 6 Mataram dan SMAN 8 Mataram menunjukkan 
bahwa penguasaan konsep peserta didik yang mencakup tiga kategori yaitu Tidak Paham Konsep sebesar sebesar $51 \%$ dengan jumlah peserta didik sebanyak 144 orang, Miskonsepsi sebesar 38\% dengan jumlah peserta didik sebanyak 106 orang dan Paham Konsep sebesar 38\% dan 11\% dengan jumlah peserta didik sebanyak 30 orang.

\section{DAFTAR PUSTAKA}

[1] Dahar, R. W. 2011. Teori-Teori Belajar dan Pembelajaran. Jakarta : Erlangga.

[2] Johnson, D.W.and Johnson, R.T. (1998) Cooperative Learning and Social Interdependence Theory. [online].

[3] Engelhardt, P.V. and Bechner, R.J. (2004) Students Understanding of Direct Current Resistive Electrical Circuits. American Journal of Physics.

[4] Tekkaya, C. 2002. Misconception as Barrier to Understanding Biology. Hacettepe Üniversitesi Eğitim Fakültesi Dergisi. 23, 259266.

[5] Wijayanti, A. (2016). Implementasi model pembelajaran kooperatif tipe tgt sebagai upaya meningkatkan pemahaman konsep fisika dasar mahasiswa pendidikan IPA. Jurnal Pijar Mipa, 11(1).

[6] Putri, L. O. L., Rahman, T., \& Priyandoko, D. (2017, February). Analyzing Concepts Mastery and Misconceptions About Evolution of Biology Major Students. In Journal of Physics: Conference Series (Vol. 812, No. 1, p. 012083). IOP Publishing.

[7] Ardiyanti, Y., \& Utami, M. R. (2018). Identifikasi Miskonsepsi Siswa Pada Materi Sistem Reproduksi. Biosfer: Jurnal Biologi dan Pendidikan Biologi, 2(2), 18-23.

[8] Taufiq, L., Sriyati, S., \& Priyandonko, D. (2017, December). Students' Conceptual Change On Human Reproduction Concept Using Scientific Approach. In International Journal of Science and Applied Science: Conference Series (Vol. 2, No. 1, pp. 216226).

[9] Ramadhani, R., \& Asiah, M. D. (2016). Identifikasi Miskonsepsi Siswa pada Konsep Sistem Reproduksi Manusia Kelas XI IPA SMA Unggul Ali Hasjmy Kabupaten Aceh Besar. Jurnal Ilmiah Mahasiswa Pendidikan Biologi, 1(1).

[10] Chaniarosi, L. F. (2014). Identifikasi Miskonsepsi Guru Biologi SMA Kelas XI IPA pada Konsep Sistem Reproduksi Manusia. Jurnal EduBio Tropika, 2(2).
[11] Wahyuningsih, W., Jamaluddin, J., \& Karnan, K. (2015). Penerapan pembelajaran Biologi berbasis macromedia flash dan implikasinya terhadap keterampilan metakognitif dan penguasaan konsep siswa kelas VIII SMPN 6 Mataram. Jurnal Pijar MIPA, 10(1).

[12] Maesyarah, M., Jufri, A. W., \& Kusmiyati, K. (2015). Analisis Penguasaan Konsep Dan Miskonsepsi Biologi Dengan Teknik Modifikasi Certainty Of Response Index Pada Siswa Smp Se-Kota Sumbawa Besar. Jurnal Pijar Mipa, 10(1).

[13] Kusmiyati, K., Merta, I. W., \& Bahri, S. (2016). Studi Pengetahuan Tentang Menstruasi Dengan Upaya Penanganan Dismenore Pada Mahasiswa Pendidikan Biologi. Jurnal Pijar Mipa, 11(1).

[14] Purwanto, 2010. Evaluasi Hasil Belajar. Jogjakarta : Pustaka Pelajar.

[15] Nabilah, A. Y. \& Laksmiwati, D. 2014."Analisis Tingkat Pemahaman Konsep Siswa Kelas XI IPA SMA N 3 Mataram Menggunakan One Tier Dan Two Tier Test Materi Kelarutan dan Hasil Kali Kelarutan". Jurnal Pijar MIPA, 2, 64-69.

[16] Siswaningsih, W. (2014). Pengembangan tes diagnostik two-tier untuk mengidentifikasi miskonsepsi pada materi kimia siswa SMA. Jurnal Pengajaran MIPA, 19(1), 117127.

[17] Suparno, P. 2013. Miskonsepsi Perubahan Konsep Dalam Pendidikan Fisika. Jakarta : PT. Grasindo.

[18] Hamalik. 2002. Metode Belajar dan Kesulitankesulitan Belajar. Jakarta : Gramedia.

[19] Murni, D. 2013. Identifikasi Miskonsepsi Mahasiswa pada Konsep Substansi Genetika Menggunakan Certainty of Response Index (CRI). Prosiding Semirata FMIPA Universitas Lampung.

[20] Onansaya. 2004. Selection and Utilization of Instructional Media for Effective Practice Teaching. Institute Journal of Studies in Education vol. 2 (1):127-133.

[21] Jufri, A. W. 2013. Belajar dan Pembelajaran Sains. Bandung: Pustaka Reka Cipta. 